\title{
Dispersion of Particulate Matter and Sulphur Oxides from Thermal Power Plant: A case study
}

\author{
Jayant Singh, R. Srikanth and Sheela K. Ramasesha* \\ Energy and Environment Research Programme \\ School of Natural Sciences and Engineering \\ National Institute of Advanced Studies \\ Indian Institute of Science Campus \\ Bengaluru 560012, India.
}

\begin{abstract}
:
Coal-fired thermal plants (CTPP) are known to pollute the atmosphere with emission of many greenhouse gases and particulate matter. The power generation from these thermal plants cannot be stopped completely because it forms the backbone of the grid power supply. It is necessary to study the dispersion patterns of pollutants that affect the health of the people. The dispersion patterns are location specific since they depend on local meteorological conditions. In this study, the dispersion of particulate matter (PM) and sulphur dioxide $\left(\mathrm{SO}_{2}\right)$ from a CTPP with $275 \mathrm{~m}$ high stack are studied under different atmospheric boundary layer $(\mathrm{ABL})$ of neutral, stable and unstable conditions up to a distance of $30 \mathrm{~km}$ from the stack. The plume of the PM spreads under all conditions. During some parts of the day, PM settles around the stack while at other times PM keeps suspending in the air for the full distance under study. Sulphur dioxide dilutes to concentrations below the detection limits in about $12-13 \mathrm{~km}$ from the stack for neutral and unstable $A B L$ whereas for the stable $A B L$, the dispersion is up to $30 \mathrm{~km}$. The $24 \mathrm{~h}$ weighted average concentration of sulphur dioxide, at $10 \mathrm{~m}$ height from the ground, is $14.2 \mu \mathrm{g} / \mathrm{m}^{3}$ at a distance of $25 \mathrm{kms}$ from the CTPP, which is comparable with the value of $9.2 \mu \mathrm{g} / \mathrm{m}^{3}$ measured at the Air Quality Stations located around the same distance. Based on the results policy changes that need to be implemented are suggested.
\end{abstract}

Keywords: Coal-fired Thermal Plants, CFD modelling, Pollution, Particulate matter, Sulphur dioxide

*sheela.ramasesha@gmail.com 


\section{Introduction}

Coal Thermal Power Plants (CTPP), in addition to releasing $\mathrm{CO}_{2}$, one of the greenhouse gases that leads to global warming, also emit pollutants like $\mathrm{SO}_{x}, \mathrm{NO}_{x}$ and particulate matter. This has been a concern all over the world and many studies have been carried out in this regard (Xu et al., 2017; WiatrosMotyka, 2019; Gibson et al. 2013). These pollutants have a relatively acute impact on human health, and as studies have shown, it has become a significant cause of premature deaths in developing countries (Backes et al. 2013; Cohen et al., 2017). In India, 1.24 million deaths in 2017 were attributed to air pollution, out of which 0.67 million deaths were due to particulate matter (PM) pollution (Balakrishnan et al., 2019). In addition to factors like construction activity, transport vehicular movement, and stubble burning, combustion of coal in thermal power plants for power generation is a significant source of particulate matter pollution. In addition to the health of humans, there are many environmental effects on the flora and fauna on surrounding areas due to the pollutant dispersion of the flue gas from CTPPs (Pokale 2012; Vasistha 2014). Pollutants can spread over as far as $25 \mathrm{kms}$ from the power plant.

There is a strong relationship between Human Development Index (HDI) and Per capita energy consumption. India has to quadruple its per capita energy consumption to reach a HDI of 0.8 (from the current level of 0.64 ) to join the group of countries with high human development (MoF, 2018). India meets more than 70\% percent of the total electricity demands through CTPP (CEA Annual Report, 2018-19). Studies have found that hamlets in the vicinity of CTPP are at a higher risk of exposure to the emissions. Therefore, Central Pollution Control Board (CPCB), India mandates a minimum stack height of $275 \mathrm{~m}$ for a coal power plant for units with capacities greater than $500 \mathrm{MW}$, to maximize the dilution of pollutants after their release from the stack (CPCB, 1985).

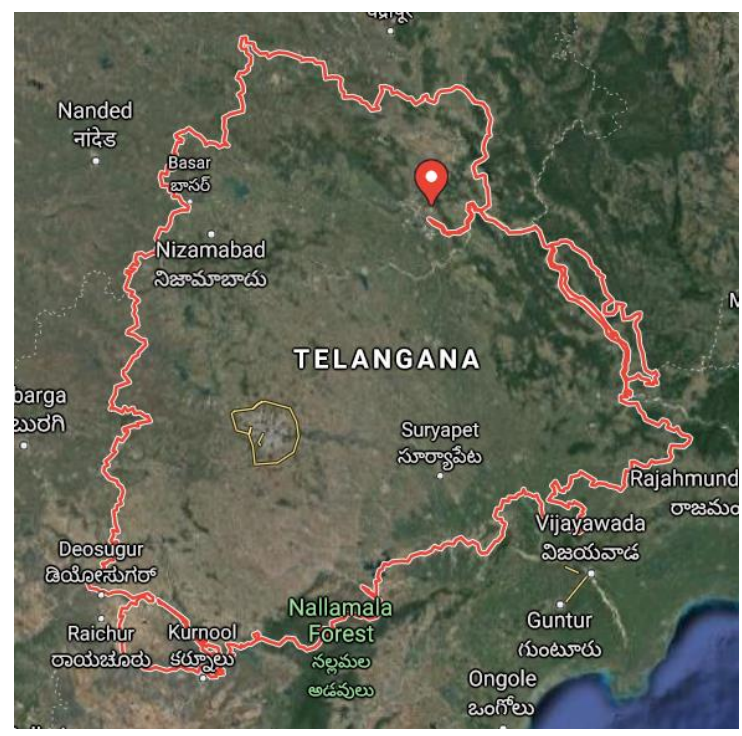

Figure 1: Map of Telangana state with SCCL Thermal Plant marked.

The current study attempts to simulate the dispersion of pollutants with real emission data from the $275 \mathrm{~m}$ tall stack of a CTPP using a commercially available computational fluid dynamics (CFD) software package (Ansys Fluent). The chosen CTPP is located in the state of Telangana, India (fig 1) and uses locally available coal as fuel to generate electricity. The stack data, like, average flue gas and pollutant flow rate, stack height, and diameter, are obtained from the power plant's Environmental Impact Assessment report. The report also included the meteorological data, which comprised of wind speed 
and stability class data for the post-monsoon (October and November) period. The methodology of the current simulation is developed from an extensive literature survey of studies (Tominaga and Stathopoulos, 2018 ; Li et al., 2006; Tominaga and Stathopoulos, 2010; Scargiali et al., 2005; Zhang, 2009; Riddle et al., 2004) that have used CFD techniques to study the dispersion of pollutants/gases out of the stack/point source and studies that have simulated the atmospheric boundary layer (ABL). Most of the studies related to the simulation of $A B L$ have predominantly dealt with the neutral boundary layer, and very few studies have carried out simulation of the unstable and stable class of ABL. Most of such studies (Sahebnasagh et al., 2008; Kozić et al., 2015), have only used temperature as a major parameter to characterise other stability classes and use simpler or single profile like the neutral log or power velocity profile, for all stability classes. The empirical equations that relate vertical distance, together with other parameters like wind velocity and turbulence, are available in the literature. The velocity profile for each case equation for turbulent kinetic energy and turbulence dissipation rate in the present study are computed using equations from other studies (Arya, 1995, Han et al., 2000). These equations are incorporated into the calculations in the present study to elucidate the dispersion profiles of both particulate and the gaseous components.

CFD modelling has emerged as a powerful tool for design and development of coal furnaces. Complex physical and chemical processes of combustion can be handled accurately through detailed simulation tools and suitable sub-models. Numerical methods remain the only tool to model the wind flow profiles and dispersion of pollutants, within indoor structures and over complex outdoor structures. Numerical methods, unlike the parametric methods, capture the underlying phenomena behind the dispersion of pollutants like fluid flow, thermal effects, turbulence, etc. because of which, it requires expert knowledge of the domain and higher computational capital, compared to the parametric analysis tools. These methods are used in applications involving biomass heating systems (Tong et al. 2017), in industrial processes (Stopford 2002), dispersion of pollutants in industrial areas (Sahar et al. 2014; Riddle et al. 2004), mineral particles dispersion from quarry (Sivester et al. 2009) and many more. However, it is a challenge to validate a numerical dispersion model over a complex geometrical set up. The current study attempts to recreate a validated study over for simple geometry and extend the model to different stability classes, before its possible extension to complex geometries for further studies.

\section{Methodology}

The three-dimensional RANS equations which are basically a set of mass and momentum conservation equations, are solved to obtain the flow parameters at discrete points within the defined simulation domain. The unknown value for Reynolds stress terms go in, as input to the RANS equations upon the selection of the turbulence model. For the case, Reynolds Stress model is chosen out of the many available turbulence models in Fluent library, for its anisotropic treatment of the turbulence terms and better results in dispersion simulation as demonstrated in studies like Riddle et. al., 2004, Dehbi 2006, Chen et al. 2010, Gorlé et al. 2009 and Gorlé et al. 2010. The discretization and solution method opted were the, second order upwinding for pressure and the QUICK scheme for other terms with least square cell based gradient calculator for higher accuracy.

Fluent offers two broad approaches to study the dispersion of a species/phase within a primary phase, namely the Eularian and Langerian approach. In the Eularian approach, all phases that are a part of the fluid flow simulation, are treated as continuous phases and the RANS equations are solved for 
each phase separately to get the flow pattern for each control volume. In the Langerian approach however, the secondary phase is treated as a collective of large but representative number of particles and the trajectory of each particle is calculated under the effect of all forces acting on the particle. The trajectory followed by each particle is stored on a file, along with the residence time, which is then later used to calculate the concentration of the secondary phase along the flow field. It is also called the discrete phase method (DPM) in Fluent.

Trajectory calculations of these particles become complicated, when the flow is in the turbulent regime due to the random changes in the flow field and in turn in the particle flow. The Eddy interaction model (EIM) which is a stochastic random walk model and is available within Fluent, is used in this study to describe the random motion of the particles. The length of the eddy $\left(L_{e}\right)$ and the Langarian Integral time scale $\left(T_{L}\right)$ are given by equations (1) and (2), where $C_{\mu}$ and $C_{L}$ are constants. $A$ value of 0.3 is input for $C_{L}$ for the case of RSM turbulence model.

$$
\begin{gathered}
L_{e}=\left(C_{\mu}\right)^{\frac{3}{4}} \frac{K^{\frac{3}{2}}}{\varepsilon} \\
T_{L}=C_{L} \frac{K}{\varepsilon}
\end{gathered}
$$

The instantaneous velocity field is generated from the mean velocity field $(\bar{u})$ using the Reynolds decomposition, of which the instantaneous or the fluctuating term $\left(u^{\prime}\right)$ is assumed to follow the Gaussian Probability distribution. In the RSM turbulence model, the value of the velocity fluctuations can be obtained by using equation (3)-(5), where, $\zeta$ is a normally distributed random number.

$$
\begin{aligned}
& u^{\prime}=\zeta \sqrt{\overline{u^{\prime 2}}} \\
& v^{\prime}=\zeta \sqrt{\overline{v^{\prime 2}}} \\
& u^{\prime}=\zeta \sqrt{\overline{u^{\prime 2}}}
\end{aligned}
$$

The random eddy lifetime $\left(\tau_{\mathrm{e}}\right)$ is chosen, which is given by equation (6) and where $r$ is a random number uniformly distributed over 0 and 1 .

$$
\tau_{e}=-T_{L} \log (r)
$$

The time that particle takes to cross the length of the eddy is given by equation (7). The smaller value out of the eddy lifetime and the eddy crossing time ( $\left.t_{\text {cross }}\right)$ is taken to be the particle-eddy interaction time.

$$
t_{\text {cross }}=-T_{L} \ln \left[1-\left(\frac{L_{e}}{\tau\left|u-u_{p}\right|}\right)\right]
$$

Where, $\tau$ is the relaxation time and $\left|u-u_{p}\right|$ is the relative velocity between the particle and the interacting fluid phase. 


\subsection{Geometry:}

A three-dimensional cuboid with dimensions: $30 \mathrm{~km}(\mathrm{~L}) \times 5 \mathrm{~km}(\mathrm{H}) \times 1.2 \mathrm{~km}(\mathrm{~W})$ was constructed using Ansys Spaceclaim, to simulate the atmosphere. A cylindrical stack of height $275 \mathrm{~m}$ and a diameter of $7 \mathrm{~m}$ was placed inside the domain at $500 \mathrm{~m}$ in the downwind direction from the wind inlet face. The domain was meshed using the Ansys Meshing, such that, cells closest to the ground have a height of $0.5 \mathrm{~m}$ and cells near the stack outlet are refined such that there are at least 10 cells across the plume width (Riddle et al., 2004).

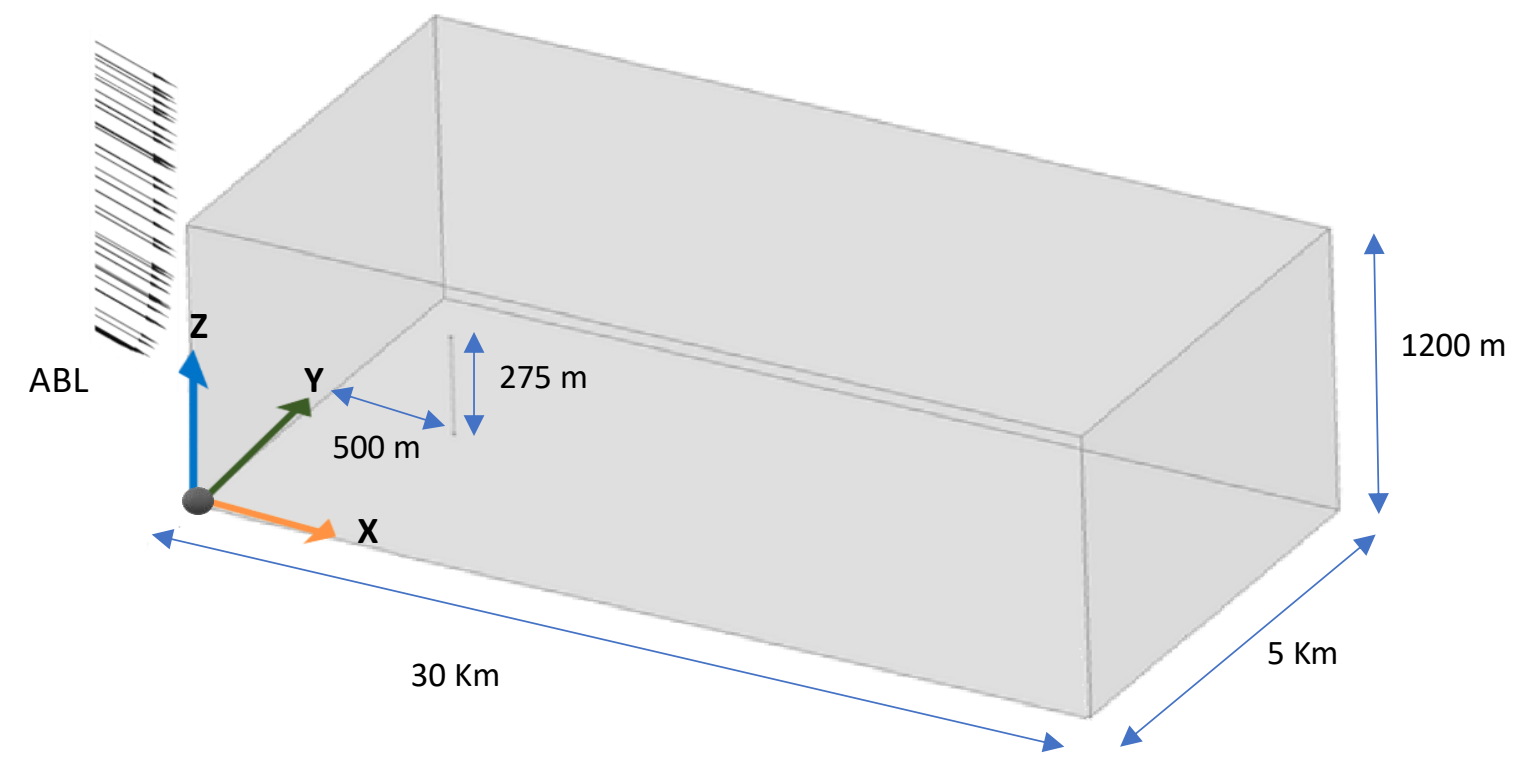

Figure 2: A representation of the simulation domain with the specified dimensions (not to scale).

\subsection{Boundary conditions:}

$A B L$ forms the lowest part of the troposphere, in which the wind flow is influenced by the mechanical and thermal stresses generated during the air-surface interaction. The mechanical stresses are generated due to the friction exerted by the ground on the wind flow and the thermal effects are caused due to the heat flux the air receives from the heated earth surface. The earth's surface is heated from the energy it absorbs from the sun's radiation, which has a diurnal pattern and therefore the turbulence created has a similar pattern. This variation is such that, during the day when the earth's surface is heated, a convective flow regime is observed, like during late mornings to evening and when the sun is absent, thermal stratification occurs, like at nights. During the transition between the two, occurs a point when thermal processes are absent, which is when the resultant ABL is called the neutral boundary layer (early mornings). The convective boundary layer is called the Unstable boundary layer and the thermally stratified $A B L$ is called the Stable boundary layer or the nocturnal boundary. The wind flow patterns are significantly different for the diurnally varying $A B L$ (which are also called stability classes) and therefore require to be modelled individually to understand the pollutant dispersion in each case (Randerson, 1995).

Convergence of the numerical problem significantly depends on the provided boundary conditions. Parameters to characterize and simulate the atmospheric boundary layer for different atmospheric stability classes were obtained from the literature. The height of the Atmospheric Boundary layer and the stability class of the boundary layer are the two most important parameters used to characterize it. The height of the boundary layer is given by Equation (8) for the case of Neutral boundary layer and Equation (9) for Stable boundary layer. 


$$
\begin{gathered}
h=\frac{0.3 u_{*}}{|f|} \\
h=0.4\left(\frac{L u_{*}}{|f|}\right)^{\frac{1}{2}} \\
f=2 \Omega \sin (\phi)
\end{gathered}
$$

where $f$ is the Coriolis parameter, $\phi$ is the latitude which equal to 0.35 radians for this case, and $\Omega=$ $7.292 \times 10-{ }^{5} \mathrm{rad} / \mathrm{s}, u_{*}=$ friction velocity, $\mathrm{L}=$ Obukhov Length and $\mathrm{h}=$ Boundary layer height (Sugiyama and Nasstrom, 1999). However, no such relation exists for Unstable class, and requires an assumption for calculations. The values of boundary layer heights obtained are compared to the previously recorded heights and appropriate values are chose for calculations.

\subsubsection{Parameterization of the atmospheric boundary layer:}

\subsubsection{Neutral boundary layer:}

\section{Velocity}

$$
u=\frac{u_{*}}{k}\left[\ln \left(\frac{Z}{z_{0}}\right)\right]
$$

For $z \leq h$

Where, $k=0.4$ (von Karman constant), $z_{0}=$ Surface roughness parameter

The velocity above the height of the boundary layer is assumed to be constant, since the effect of ground friction and buoyancy effects are negligible. For the same reason, Turbulent Kinetic (K) and Turbulence dissipation rate $(\varepsilon)$ are zero for heights above the boundary layer height.

\section{Turbulent kinetic energy profile}

For $z \leq 0.1 h$

$$
K=6 u_{*}^{2}
$$

For $0.1 h<z \leq h$

$$
K=6 u_{*}^{2}\left(1-\frac{z}{h}\right)^{1.75}
$$

Where, $z=$ vertical distance

\section{Turbulence dissipation profile}

For $z \leq 0.1 \mathrm{~h}$

$$
\varepsilon=\frac{u_{*}^{2}}{k z}\left(1.24+4.3 \frac{z}{L}\right)
$$

Temperature gradient

$$
-1.5 K / 100 m \leq \Delta T / \Delta z<-0.5 K / 100 m
$$


Where, $\Delta T / \Delta z$ is the temperature gradient versus vertical distance

\subsubsection{Stable Boundary layer:}

\section{Velocity}

For $z \leq 0.1 \mathrm{~h}$

$$
\begin{gathered}
u=\frac{u_{*}}{k}\left[\ln \left(\frac{Z}{z_{0}}\right)-\psi_{m}\left(\frac{Z}{L}\right)\right] \\
\psi_{m}\left(\frac{Z}{L}\right)=-5 \frac{Z}{L} \\
u=u_{s}+\frac{z-h_{s}}{h-h_{s}}\left(u_{h}-u_{s}\right)
\end{gathered}
$$

For $0.1 h<z \leq h$

Here, $\psi_{m}$ is the stability dependent Monin-Obukhov (MO) similarity function, $h_{s}$ is the height of the surface layer and $u_{s}$ is the wind speed at the top of surface layer.

\section{Turbulent kinetic energy profile}

$$
\begin{array}{lc}
\text { For } z \leq 0.1 h & K=6 u_{*}^{2} \\
\text { For } 0.1 h<z \leq h & K=6 u_{*}^{2}\left(1-\frac{z}{h}\right)^{1.75}
\end{array}
$$

\section{Turbulence dissipation profile}

For $z \leq 0.1 \mathrm{~h}$

$$
\varepsilon=\frac{u_{*}^{2}}{k z}\left(1.24+4.3 \frac{Z}{L}\right)
$$

For $0.1 h<z \leq h$

$$
\varepsilon=\frac{u_{*}^{2}}{k Z}\left(1.24+4.3 \frac{Z}{L}\right)\left(1-0.85 \frac{Z}{h}\right)^{1.5}
$$

Temperature gradient

$$
1.5 \mathrm{~K} / 100 \mathrm{~m} \leq \Delta T / \Delta z<4 k / 100 m
$$

\subsubsection{Unstable boundary layer:}

Velocity

For $z \leq 0.1 \mathrm{~h}$

$$
u=\frac{u_{*}}{k}\left[\ln \left(\frac{Z}{z_{0}}\right)-\psi_{m}\left(\frac{Z}{L}\right)\right]
$$

$$
\begin{gathered}
\psi_{m}\left(\frac{Z}{L}\right)=2 \ln \left(\frac{1+x}{2}\right)+\ln \left(\frac{1+x^{2}}{2}\right)-2 \tan ^{-1} x+\frac{\pi}{2} \\
x=\left(1-15 \frac{Z}{L}\right)^{\frac{1}{4}} \\
u=\frac{u_{*}}{k}\left(\ln \left(\frac{h}{z_{0}}\right)-\frac{1}{2} \ln \left(\frac{h}{|L|}\right)-2.3\right)
\end{gathered}
$$




\section{Turbulent kinetic energy profile}

For $z \leq 0.1 \mathrm{~h}$

$$
\begin{gathered}
K=0.36 w_{*}^{2}+0.85 u_{*}^{2}\left(1-3 \frac{z}{L}\right)^{\frac{2}{3}} \\
K=\left(0.36+0.9\left(\frac{z}{h}\right)^{\frac{2}{3}}\left(1-0.8 \frac{z}{h}\right)^{2}\right) w_{*}^{2} \\
w_{*}=\left(\frac{g}{T_{0}}\left(Q_{S}\right) h\right)^{\frac{1}{3}}
\end{gathered}
$$

Here, $w_{*}$ is the convective velocity scale, $T_{0}$ is the reference temperature and $\mathrm{Q}_{s}$ are the kinematic surface heat flux.

\section{Turbulence dissipation profile}

For $z \leq 0.1 h$

$$
\begin{aligned}
& \varepsilon=\frac{u_{*}^{3}}{k z}\left(1+0.5\left|\frac{z}{L}\right|^{\frac{2}{3}}\right)^{\frac{3}{2}} \\
& \varepsilon=\frac{w_{*}^{3}}{h}\left(0.8-0.3 \frac{z}{h}\right)
\end{aligned}
$$

Temperature gradient

$$
\Delta T / \Delta z<-1.9 \mathrm{~K} / 100 \mathrm{~m}
$$

$\mathrm{u} *$ is calculated from the velocity profile equation for each stability class by incorporating the known value of wind speed at a given height in the above equation. This completes the required parameters to get the complete velocity, turbulent kinetic energy and turbulence dissipation rate profile versus height in case of neutral stability class. This is a simplification introduced into the calculation, which means that the shear stress is assumed constant throughout the boundary layer, as $\mathrm{u} *$ is a function of shear stress and therefore would vary with height as well. Further, in the case of stable and unstable stability classes, another parameter called the Obkhov length $(L)$ is required to define the velocity profile and kinematic surface heat flux, for the turbulent kinetic energy profile and turbulence dissipation rate profile. In the current study, the value of $L$ is assumed from a correlation between $L$ and roughness height (presumed to be $0.1 \mathrm{~m}$ in this case) and stability class (Golder, 1972). For the assumed roughness length, $\mathrm{L}^{-1}$ varies from -0.14 to -0.1 for the stability class $A$ and from 0.04 to 0.1 for stability class F. For initial calculations, mid values from the ranges specified are chosen and then further sensitivity analysis are conducted. Kinematic Surface heat flux $\left(Q_{s}\right)$ is calculated from the assumed value of $L$, using equation (35), where $T_{0}$ is the reference surface temperature.

$$
Q_{s}=-\frac{u_{*}^{3}}{k\left(\frac{g}{T_{0}}\right) L}
$$

Equations (11-34) are written into User Defined Functions (UDFs), which are then interpreted as input for velocity, turbulent kinetic energy, turbulence dissipation rate and temperature profiles as boundary conditions to wind velocity inlet. 


\subsubsection{Stack input, Meteorological Data and Air Quality measurement stations:}

Stack details which were used to define the boundary condition of the plume inlet into the simulation domain are as given in Table 1.

Table 1: Stack input details

\begin{tabular}{|l|l|}
\hline Stack Height (along the $\mathrm{z}$ direction): & $275 \mathrm{~m}$ \\
\hline Stack Diameter & $7 \mathrm{~m}$ \\
\hline Stack position on the XY plane & $\mathrm{X}=500 \mathrm{~m}, \mathrm{y}=2500 \mathrm{~m}$ \\
\hline Emission rate of $\mathrm{SO}_{2}$ & $0.89 \mathrm{~kg} / \mathrm{s}$ \\
\hline Emission rate of Particulate Matter & $0.066 \mathrm{~kg} / \mathrm{s}$ \\
\hline Total Flue gas emission rate & $847 \mathrm{~m}^{3} / \mathrm{s}$ \\
\hline Temperature of the plume & $405 \mathrm{~K}$ \\
\hline
\end{tabular}

The meteorological data like ground temperature and wind speed were measured on site using standard equipment. During post-monsoon period the wind direction is predominantly towards north east of the CTPP. Hence the calculation are carried out taking the direction into account.

Three air quality monitoring stations are located at hamlets in the downstream wind direction during post-monsoon season at distances of $20-25 \mathrm{~km}$ from the thermal power plant under consideration. The measurements at these stations are at a height of $10 \mathrm{~m}$ and $24 \mathrm{~h}$ average data are recorded at fortnightly intervals. In this study, the average of the measurements from all the three stations during the entire season is considered.

\section{Results and Discussion:}

In this section, results obtained from the simulation of the $A B L$ are presented, which includes the profiles of key parameters across the domain for every stability class and dispersion trends of pollutants as their concentration profiles within the simulation domain. The different ABLs correspond to the situation at different times of the day. For example, stable $A B L$ exists during nights when there is no heat flux, unstable during afternoons when the solar heat generates turbulence in the atmosphere and neutral between the two, in other words, during mornings and late evenings.

\subsection{Profiles of Velocity, turbulent kinetic energy and turbulent dissipation rate across the domain:}

\subsubsection{Neutral:}

In the case of Neutral Stability class, the velocity profile and temperature are maintained well across the domain. The variation in velocity is around five percent on an average with maximum variation, both in absolute and percent terms, observed close to the ground. At heights lower than sixty meters, the average variation is around 17 percent which declines to 1.37 percent for height greater than sixty meters. However, Turbulent Kinetic Energy show major variation across the domain. The TKE's input profile, reaches its maximum at around fifteen meters and then declines linearly to zero at five hundred meters. Below 500 meters the values of TKE drop by 70- 80 percent and between $400-700$ meters, showed a positive deviation. This is in line with the results obtained by Riddle et al, 2004 which reported a $78 \%$ reduction from the inlet values of TKE. The turbulence dissipation rate profile is maintained well across the horizontal within the initial input of the boundary layer height but shows 
an increasing trend at heights greater than that. The temperature profile maintains the input linear trend for major part of the ABL height, with a deviation of less than $2 \mathrm{~K}$, near the ground.

\subsubsection{Unstable:}

The simulations of unstable boundary layer were conducted with similar mesh inputs as for the case of neutral stability class. It is seen that except for turbulence dissipation rate, none of the parameters are maintained well across the domain. Variation in velocity over the domain in this case, showed declining trend with respect to height. Within ten meters from the ground, a 30-40\% variation was observed over a domain length of $29000 \mathrm{~m}$. Similarly, around a variation of $10-25 \%$ was obtained between 10 to 100 meters and less than $4 \%$ for height greater than $100 \mathrm{~m}$. The input temperature profile which followed a linearly decreasing trend versus height, becomes constant which hints at inter-mixing between the layers of air at different heights. The temperature gradient at $29500 \mathrm{~m}$ comes down to just $0.07 \mathrm{~K}$ per $100 \mathrm{~m}$ form $2 \mathrm{~K}$ per $100 \mathrm{~m}$, beyond a height of $200 \mathrm{~m}$. The turbulent kinetic energy profile shows the most variation along the domain length. The inlet profile of TKE which is significantly higher compared to other stability classes and has a profile such that the TKE value rises with increasing height up to the top of surface layer and then drops gradually with further increase in height. In comparison to this inlet profile, the value of TKE drops by $70-90 \%$ throughout out the vertical domain and forms a profile that fits a second order polynomial.

\subsubsection{Stable:}

In the stable class, the velocity inlet profile follows a logarithmic profile within the surface layer and then increases linearly up till the top of the boundary layer and then attains a constant value. The velocity profile at $29500 \mathrm{~m}$ shows a positive deviation in the range of $400 \%$ from the inlet profile at heights below $200 \mathrm{~m}$ and a negative deviation of 10-2 percent above that height. Even with the higher velocity obtained at heights lower than $20 \mathrm{~m}$, the profile maintains a linear trend between 20 and 600 $\mathrm{m}$. The inlet TKE profile shows, the stable class shows least turbulence, compared to other two stability classes. However, the simulation results show that, the TKE profile at 15000 and $29500 \mathrm{~m}$, increases in the horizontal direction by approximately 500 percent. In the vertical direction, turbulence is no more confined to the lower $200 \mathrm{~m}$ of the domain, displaying positive values of TKE throughout the vertical domain, at 15000 and $29500 \mathrm{~m}$. In the horizontal direction at $15000 \mathrm{~m}$, the TKE values increase by six to seven times at heights below $200 \mathrm{~m}$, relative to the input profile. Further at $29500 \mathrm{~m}$, the values decline by 30-10 percent below the height of $400 \mathrm{~m}$ and increases above that height. The turbulence dissipation rate, shows a similar trend to that of the neutral case, where an increasing trend can be seen.

\subsection{Pollutant Dispersion:}

\section{Particulate Matter (PM):}

The trajectory files obtained from the DPM simulation are written on to an external file and read using CFD Post (available within Ansys workbench). Using CFD post, the discrete position and the residence time values stored on the file are converted to concentration profiles of the pollutant which have been shown as contour plots in figure (3-5), for each stability class. 
(a)

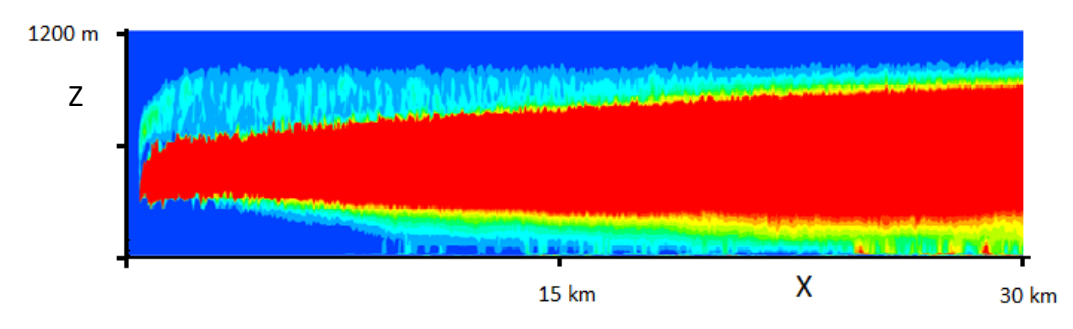

\section{Particulate matter concentration $(\mu \mathrm{g} / \mathrm{m} 3)$}

(b)

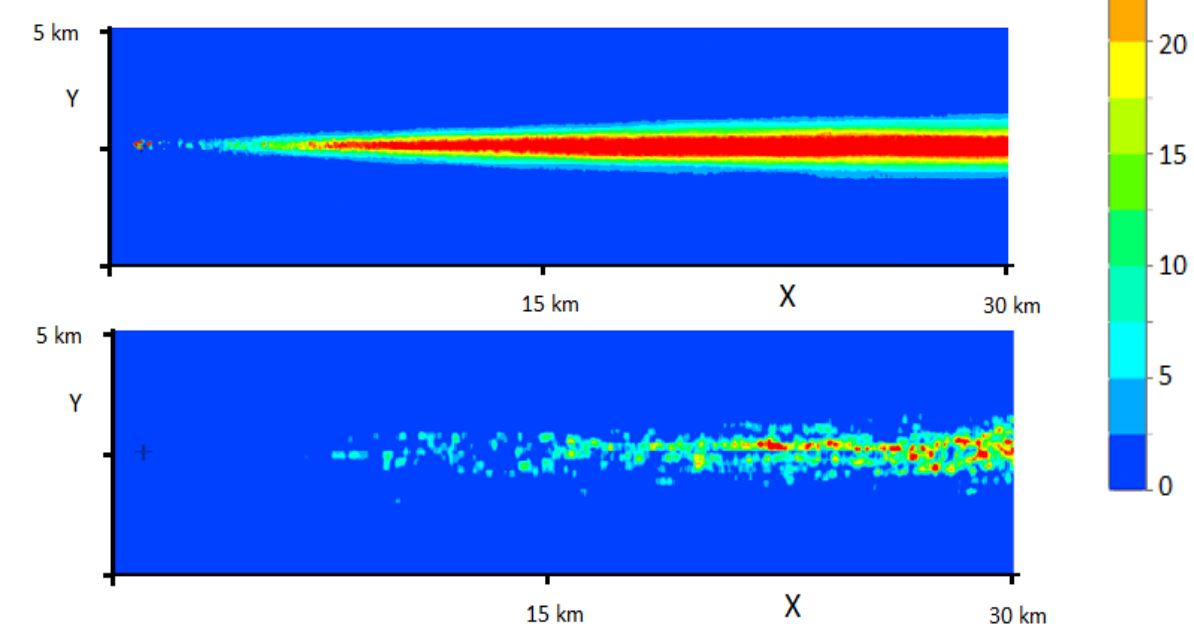

Figure 3: (a) Vertical dispersion of pollutants on a plane passing through the plume center line for neutral atmospheric conditions. (b) Horizontal dispersion of pollutants at height of the stack (275 m) for neutral atmospheric conditions. (c) Horizontal dispersion of pollutants at near ground level for neutral atmospheric conditions.

Under neutral atmospheric conditions, the vertical dispersion along the $x$ axis as shown in the figure 3 (a) on a plane passing through the center line of the plume, shows that the plume gradually spreads vertical at a rate such that the ground level concentration of pollutant goes above the $25 \mu \mathrm{g} / \mathrm{m}^{3}$ only after $25 \mathrm{~km}$. Also, the concentration at plume's center gradually falls from $5000 \mu \mathrm{g} / \mathrm{m}^{3}$ at $100 \mathrm{~m}$ after release to $100 \mu \mathrm{g} / \mathrm{m}^{3}$ at $25 \mathrm{~km}$. The height of the point of peak concentration rises and is maintained at $600 \mathrm{~m}$ after $7 \mathrm{~km}$. The horizontal plume dispersion at the stack height shows a gradual increase in width from $100 \mathrm{~m}$ at $600 \mathrm{~m}$ to $1800 \mathrm{~m}$ at $25 \mathrm{~km}$, as shown in figure 3 (b). Figure 3 (c) shows the concentration at near ground level has only small region with concentrations of $15 \mu \mathrm{g} / \mathrm{m}^{3}$ and even smaller hotspots with concentrations more than $25 \mu \mathrm{g}$, after $20 \mathrm{~km}$.

In the case of stable atmospheric conditions, it can be seen that the plume almost remains in at height of discharge as opposed to seen in the case of Neutral condition, because of the shorter mixing height of the $A B L$ under these conditions. The plume only seems to be expanding towards the ground and the center of the plume (point of maximum concentration) remains at a height of around $300 \mathrm{~m}$. The downward movement of the plume gives a higher near ground concentration and lower concentration at the height of the stack, as shown in figure 4 (b) and (c), in comparison to the neutral conditions. 
(a)

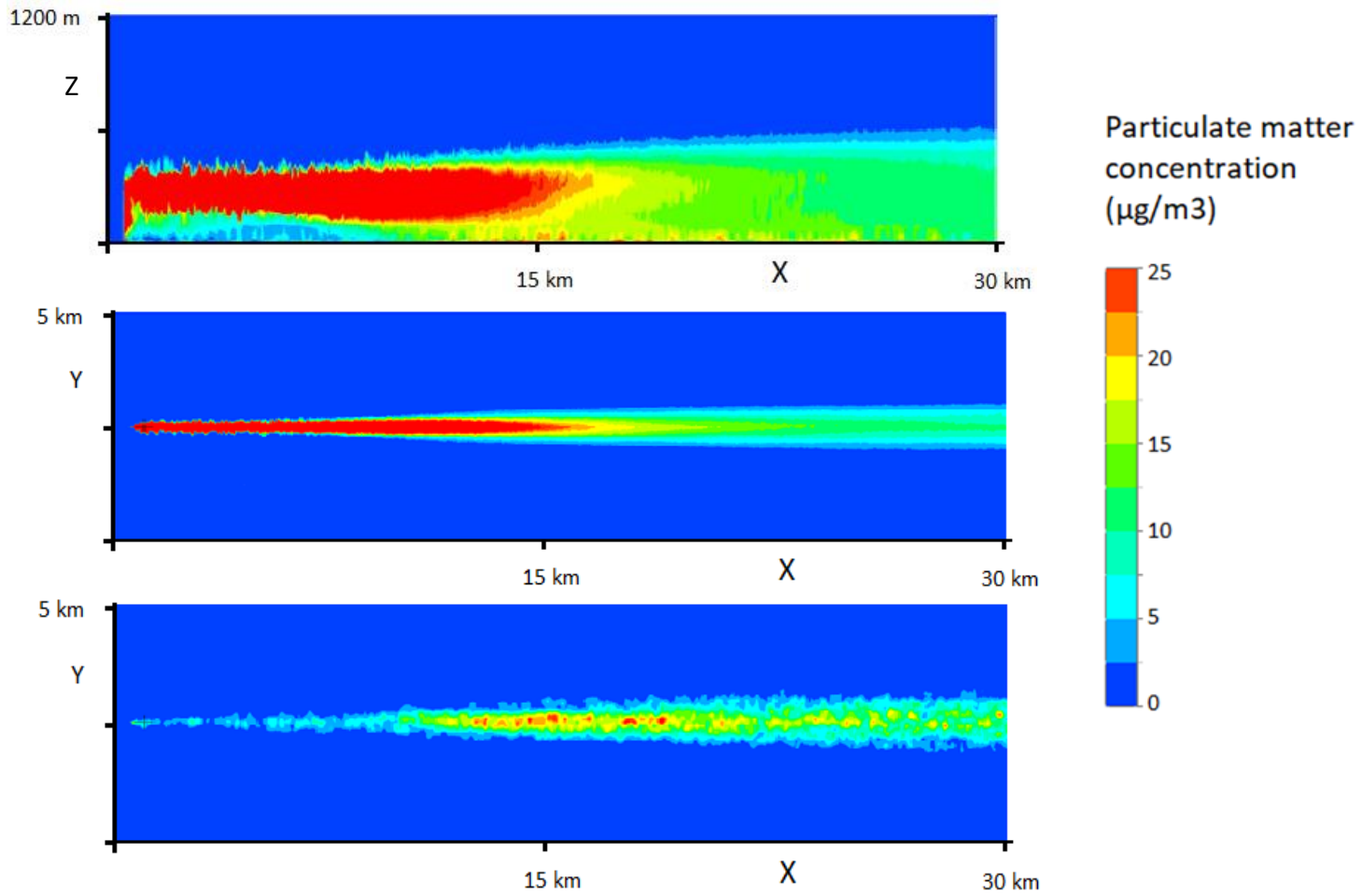

Figure 4: (a) Vertical dispersion of pollutants on a plane passing through the plume center line for stable atmospheric conditions. (b) Horizontal dispersion of pollutants at height of the stack (275 $\mathrm{m}$ ) for stable atmospheric conditions. (c) Horizontal dispersion of pollutants at near ground level for stable atmospheric conditions.

However, under unstable conditions the plume settles the fastest and a region of high concentration is developed in the region within the $10 \mathrm{~km}$ downwind direction from the point of release of the plume, at the near ground level (figure 5 (a)). The strong convective regime which is characteristic of unstable atmospheric conditions, allows for greater vertical mixing of the pollutants and also, faster dilution of the pollutant concentration in the plume. The horizontal dispersion is also much greater with a plume width of the entire $5 \mathrm{~km}$ domain just at distance of $4 \mathrm{~km}$ from the stack, at the height of stack and ground level as shown in figure 5 (b) and (c).

Thus, under neutral (during mornings and evenings) boundary layer conditions, the particulates keep floating away and the concentration at ground level is less than $15 \mu \mathrm{g} / \mathrm{m}^{3}$. These particles continue to travel and be suspended in the atmosphere at higher altitudes until they hit a physical barrier or are subjected to earthly happenings like rain/storm. During the day when unstable boundary layer prevails, the particulates settle within $15 \mathrm{~km}$ of the stack and the concentration at the ground level is as high as $25 \mu \mathrm{g} / \mathrm{m}^{3}$. At nights, the plume spreads and because of the dilution in the atmosphere, by about $17 \mathrm{~km}$ from the stack, the concentration of PM drops down to $15 \mu \mathrm{g} / \mathrm{m}^{3}$. The particulate emission from the CTPP not only settles near the plant but also suspends in the air over a long distance depending on the time of the day. An experimental study using a tethered balloon system over the city of New Delhi was conducted (Bisht, 2016). PM and black carbon concentrations were measured as a function of altitude along with other measurements both during ascent and descent. The results show multiple peaks of PM2.5, observed at around 200-300 m, $100 \mathrm{~m}$ and $50 \mathrm{~m}$, which seems in line with the results obtained from the stable boundary layer simulations. Another experimental and simulation study of black carbon concentration variation with altitude, conducted over Hyderabad, also show high concentrations of particles below $1 \mathrm{~km}$ (Govardhan et al., 2017). Both these locations have quite a few CTPPs in the vicinity. Similar altitude profiles for PM have been recorded over 
Shanghai, where there are many CTPP in the vicinity, using tethered balloon (Li J. et al. 2015). Though, it is not clear what percentage of the measured concentration profiles are due to the emissions from CTPP and how much from local pollutions. Simulations of particulates emitted from the Badarpur CTPP (this plant is inactive now), which is close to Delhi, predicted values in the range of 83.63-404.57 $\mathrm{\mu g} / \mathrm{m}^{3}$ whereas the measured 24-hourly averaged SPM concentrations for the four seasons were in the range of $244.83-664.67 \mu \mathrm{g} / \mathrm{m}^{3}$ (Goyal and Sidhartha 2004). Hence in large cities, there is local pollution in addition to the floating pollution from the CTPPs located around them.

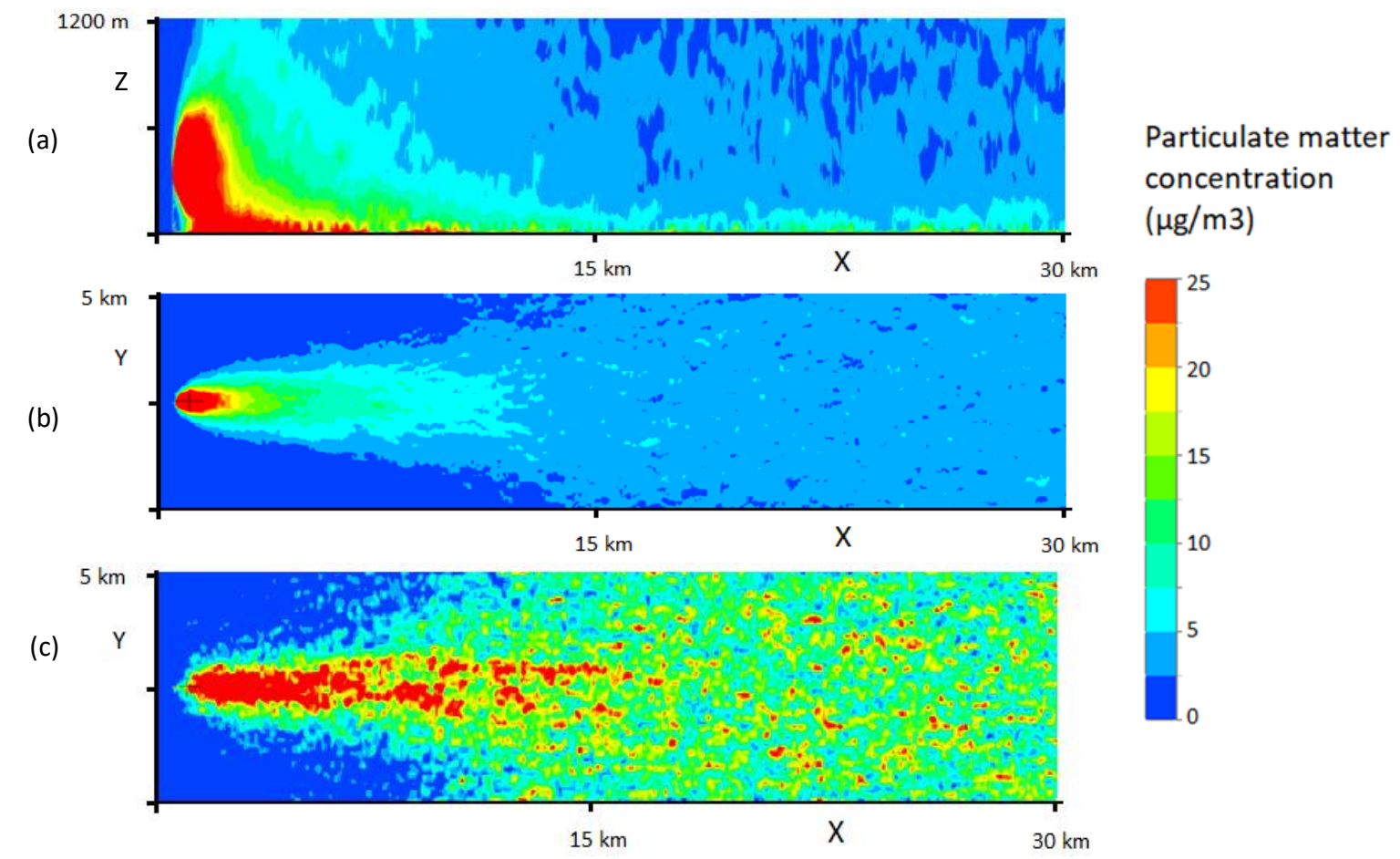

Figure 5: (a) Vertical dispersion of pollutants on a plane passing through the plume center line for unstable atmospheric conditions. (b) Horizontal dispersion of pollutants at height of the stack $(275 \mathrm{~m})$ for unstable atmospheric conditions. (c) Horizontal dispersion of pollutants at near ground level for unstable atmospheric conditions.

Many studies are carried out to reduce the particulate emission from coal combustion. Based on the source of emission, different technologies are developed to control the particulates. The level of particulate matter emission rate is achieved by employing electrostatic precipitator, bag filter, cyclone etc. The widely used technique is the bag filter. A high moisture coal particle can clog the filter (Li et al. 2015). Another way of controlling particles in coal thermal unit involves supressing the dust using water spray (Tessum and Raynor, 2017). The wet scrubbers are used for the safe control of particles emitted from coal firing plants (Schnelle and Brown, 2016). The other type of wet scrubber unit is the vortex scrubber (Brauer and Varma, 2012). CFD calculations carried out on double vortex scrubber concluded that the performance is better with a double vortex system than a single vortex system (Kim et al. 2019). In order to impede the flow of dust and smoke, a filtration device like the electrostatic precipitator (ESP) are also studied (Gromaszek et al. 2016). All these studies have suggested ways to control the particulate emissions from the stacks of the CTPPs. The older plants are still operational in India and retrofitting the new technologies to control PM emissions may not be feasible or cost-effective. The high-altitude particulate dispersion is ignored by the coal thermal plant industry and is a cause of concern. 


\section{Sulphur Dioxide $\left(\mathrm{SO}_{2}\right)$ :}

The $\mathrm{SO}_{2}$ concentration profiles obtained from the Eularian method, are presented as contour plots in the figure 6 for neutral, stable and Unstable conditions. As seen in the contour plots, the dispersion of pollutant observed in the case of Neutral and Unstable are similar. In both cases, the pollutant volume fraction values go below the value of $1 \times 10^{-8}\left(26 \mu \mathrm{g} / \mathrm{m}^{3}\right)$ within $14 \mathrm{~km}$ from the release point. In the case of stable atmospheric conditions, the plume undergoes dilution at a much lower rate and the concentrations stays high till about $27 \mathrm{~km}$. In all the cases, the concentration drops significantly near the stack outlet but remains almost constant between $5000 \mathrm{~m}$ and $10000 \mathrm{~m}$ from the stack. Only in the case of stable class, the point of peak concentration moves downwards as the plume travels along the horizontal. However, in the case of unstable and neutral stability class, a gaussian like distribution is observed along the boundary layer height, with a difference that in the case of unstable stability class, the concentration of $\mathrm{SO}_{2}$ are much lower compared to the case of neutral stability class.

A series of sensitivity analysis for the parameters, like Obhkov Length and Temperature gradient were conducted, which did not show any significant dependence on the flow pattern. Corrections proposed by Zhang, 2009 were adopted, which worked for the simulation of neutral boundary layer but could not be extended for other stability classes. In addition to this, Lagrangian approach was adopted for gaseous phase also $\left(\mathrm{CO}_{2}\right)$, of which the result was significantly different with regards to the change in concentration versus the horizontal distance, but the height of peak concentration was similar.

The values of $\mathrm{SO}_{2}$ concentration obtained from the contour plots (figure 6) were used to get a weighted average of $\mathrm{SO}_{2}$ concentration for an entire day, at $10 \mathrm{~m}$ height from the ground for various distances along the horizontal distance. It is seen that the $24 \mathrm{~h}$ average $\mathrm{SO}_{2}$ concentration at all distances less than $30 \mathrm{~km}$ remains below the National Ambient Air Quality Standard of $80 \mathrm{\mu g} / \mathrm{m}^{3}$. There are 3 ground-based sensors located at about $20-25 \mathrm{~km}$ from the CTPP under consideration. The average of $24 \mathrm{~h}$ average from these sensors is $9.2 \mu \mathrm{g} / \mathrm{m}^{3}$ for post-monsoon season which compares well with the weighted $24 \mathrm{~h}$ average value of $14.2 \mu \mathrm{g} / \mathrm{m}^{3}$ at a distance of $25 \mathrm{~km}$ from the above calculations.

Sulphur is present in coal in inorganic and organic forms. During the combustion process, the inorganic and organic sulphur is released and converted to oxides of sulphur, $\mathrm{SO}_{2}$ and $\mathrm{SO}_{3}$. A large amount of oxides of sulphur (SOx) is emitted from coal burning which is the cause for formation of acid rain. Direct SOx gas emission into the atmosphere not only forms the urban smog but also is responsible for reactions that deplete ozone in the stratosphere. To control emissions of SOx from the CTPP, several desulfurization techniques, such as fuel pre- or post-treatment and efficient burning have been proposed (Hao et al., 2009). Among these techniques, flue gas desulphurization (FGD) is the most effective technology due to its high efficiency and availability. Even the FGD technology has a number of variations like the dry, semidry and wet scrubbers. Using SOx absorbers like $\mathrm{Ca}(\mathrm{OH})_{2}($ Wang $\mathrm{H} 2018)$, lime, phosphate and many others have been attempted (Pan S-Y et al. 2017). 


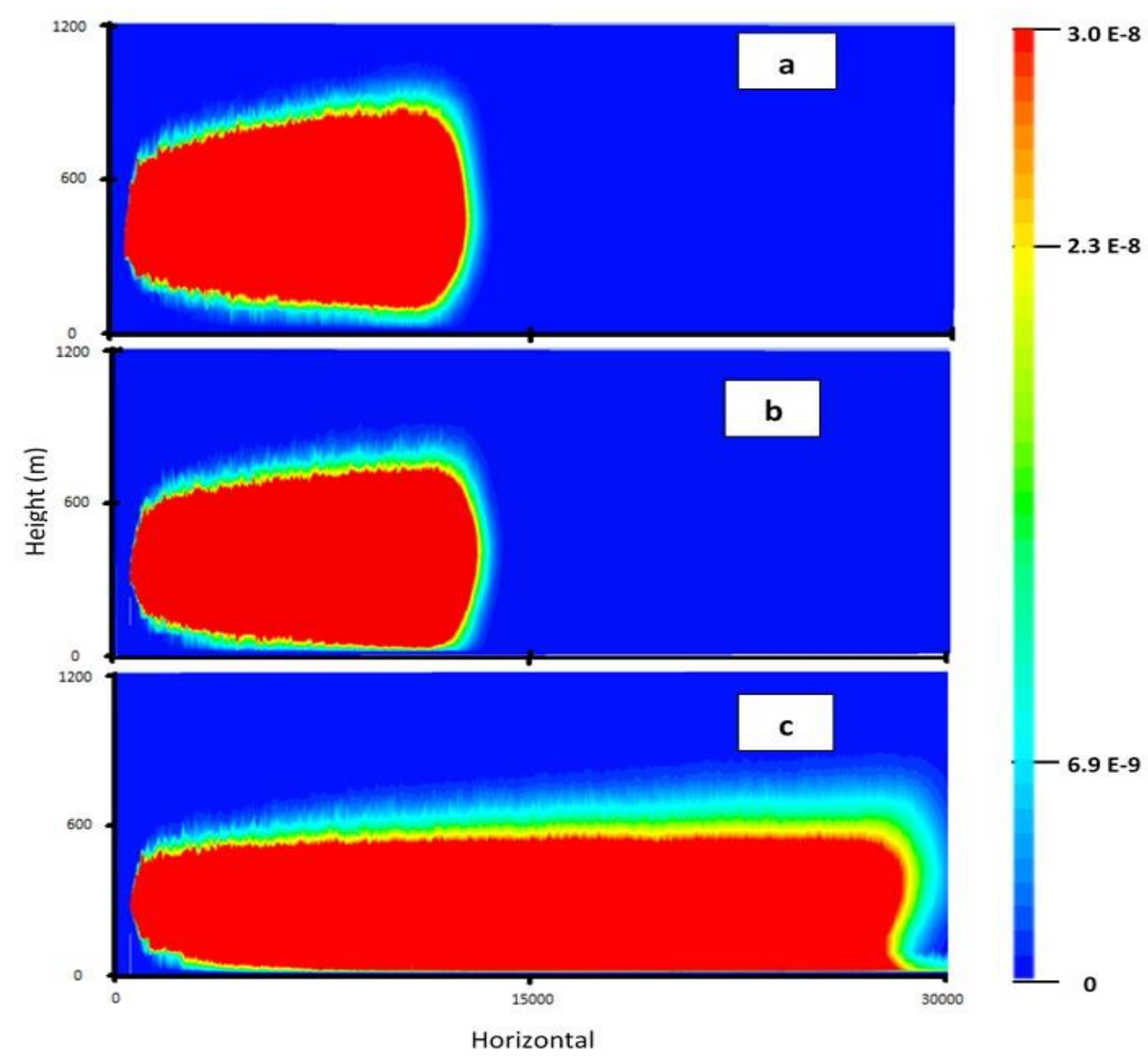

Figure 6 Contours of $\mathrm{SO}_{2}$ volume fraction obtained from the simulation of Neutral (a), Unstable (b) and Stable (c) boundary layer.

\section{Suggestions for Policy makers to control emissions:}

According to EPA (2013), "exposure to fine particle pollution can cause premature death and harmful cardiovascular effects such as heart attacks and strokes and is linked to a variety of other significant health problems." Coal Thermal Power Plants (CTPPs) emit particulate matter (PM) pollutants from their stacks as well as from activities involving storage/transportation of coal or ash. PM pollution from stockpiles can be localised by using dust suppression techniques like, water sprinkling, green belts, etc. However, PM emissions from stacks, as seen from the calculations above, spread much beyond the CTPP boundary. This is due to the fact that the height of the chimneys is designed to disperse the pollutants and dilute the pollutant concentration during all meteorological conditions to a level which will not adversely affect the environment (Thomas et al. 1963). In India, the Central Pollution Control Board (CPCB) has mandated minimum chimney heights of $220 \mathrm{~m}$ for CTPPs with a 
unit size of $200-500 \mathrm{MW}$ and $275 \mathrm{~m}$ for units of size greater than $500 \mathrm{MW}$. This was based on studies of Mean Mixing Depths (MMD) in three Indian cities (Kolkata, Delhi, and Mumbai) where the MMD was found to be $210 \mathrm{~m}$ in coastal areas and $220 \mathrm{~m}$ in the inland area of the country (CPCB, 1985). In India, PM pollutants from CTPPs are normally controlled by installing an electrostatic precipitator (ESP) which uses electrical forces to remove the PM pollutants from the flowing gas stream and deposit them on to collector plates from where they are disposed after mixing with the ash. Highefficiency ESPs are now available which can remove $99.97 \%$ of the PM pollutants at source and reduce PM concentrations in the emissions from the chimney to below $50 \mathrm{mg} / \mathrm{Nm}^{3}$ as per the current standards (MoEF\&CC, 2015). However, for CTPPs set up before 2003, the PM standard is $100 \mathrm{mg} / \mathrm{Nm}^{3}$. The Ministry of Power (MoP) and Ministry of Environment, Forest, and Climate Change (MoEF\&CC) in the Government of India have decided on an implementation plan which involves the upgradation of the ESPs in 222 CTPPs by 2022 along with the FGDs to control SOx emissions (MoP, 2018). However, there is a need to advance the upgradation of the ESPs in the country. Linking ESP upgradation to the installation of more expensive, imported FGDs is not required since the ambient concentrations of $\mathrm{SO}_{2}$ attributed to CTPPs using domestic coal in India are much less than the National Ambient Air Quality Standards of 2009 , which is $24 \mathrm{~h}$ average of $80 \mu \mathrm{g} / \mathrm{m}^{3}$ and an annual average limit of $50 \mu \mathrm{g} / \mathrm{m}^{3}$ (MoEF, 2009). This is due to the lower sulphur content of most Indian coals (0.4 - 0.7 percent) compared to thermal coals imported into India which can have sulphur contents exceeding 2 percent based on the source. While new CTPPs fitted with FGDs can have stack heights of less than $100 \mathrm{~m}$ as per CPCB norms, the TPPs commissioned prior to 2017 were approved with stack heights of 220/275 $m$ to ensure adequate dispersion of pollutants even without FGDs as per the CPCB norms (CEA, 2019). This fact is demonstrated in this study as well since the $2 \times 600$ MW CTPP modelled here is based on the coal mined within $25 \mathrm{~km}$ from the CTPP. Expediting the upgradation of ESPs will create the greatest impact on public health of communities around CTPPs in India.

\section{Conclusion:}

Coal-fired thermal plants emit many gases and fine particulate matter that are harmful to the environment and humans. Not many studies are carries out that trace the dispersion patterns of particulate matter and these dispersions are location specific because of the dependence on meteorological conditions like ambient temperature, wind velocity and direction. The dispersion of $\mathrm{PM}$ and $\mathrm{SO}_{2}$, two of the major pollutants after $\mathrm{CO}_{2}$ emitted from the stack of a thermal plant, are computed using a CFD simulation. Actual emissions from a $275 \mathrm{~m}$ tall stack and the meteorological parameters of the location are used in the simulation. Simulations are carried out for stable, neutral and unstable boundary layer conditions that represent the night, morning and afternoon situations, 
respectively. It is found that the peak PM concentration in the plume rises close to 600 and $300 \mathrm{~m}$ during mornings and nights, respectively. Thus, PM continues to suspend in the atmosphere over large distances from the CTPP, though dilution and spread of the PM occurs, during nights, at distances greater than $15 \mathrm{~km}$ from the stack. However, during neutral conditions of mornings and evenings, the high concentration of PM spreads over the entire distance of calculation of $30 \mathrm{~km}$. During afternoons, when there are thermal turbulences, the PM settles on ground within about $10 \mathrm{~km}$ from the stack.

$\mathrm{SO}_{2}$ spreads and disperses quite quickly. During morning and afternoons, within about $12 \mathrm{~km}$ from the stack, the $\mathrm{SO}_{2}$ concentration is below the measurable limit. At nights, the dispersion continues up to about $30 \mathrm{~km}$. However, the $24 \mathrm{~h}$ weighted average concentration of $\mathrm{SO}_{2}$ at $10 \mathrm{~m}$ height and at a distance of $25 \mathrm{~km}$ is $14.2 \mu \mathrm{g} / \mathrm{m}^{3}$, which compares well with the measured value of $9.2 \mu \mathrm{g} / \mathrm{m}^{3}$ that is less than the National Ambient Air Quality Standard of $80 \mu \mathrm{g} / \mathrm{m}^{3}$.

Based on the calculations, it is suggested that as a policy, the PM removal is critical and CTTPs must be fitted with appropriate technology to control PM emission. Since the stack heights are large in India and $\mathrm{SO}_{2}$ disperses quickly, fitting FGDs, though a necessity can be carried out in due course.

Acknowledgement: The authors thank the Ministry of Earth Sciences (Grant number: MoES/16/15/2011-RDEAS (NIAS)), for supporting this research. Authors also acknowledge the help received from SCCL by providing the stack data. 


\section{References}

Arya S. P., 1995, "Atmospheric Boundary Layer and Its Parameterization," Wind Clim. Cities, pp. 4166, doi: 10.1007/978-94-017-3686-2_3.

Backes, C.H., Nelin,T., Gorr,M.W. and Wold,L.E., 2013, "Early life exposure to air pollution: how bad is it?", Toxicology Letters 216, 47-53.

Balakrishnan et al., 2019, "The impact of air pollution on deaths, disease burden, and life expectancy across the states of India: The Global Burden of Disease Study 2017," Lancet Planet. Heal., vol. 3, no. 1, pp. e26-e39, doi: 10.1016/S2542-5196(18)30261-4.

Bisht et al., 2016, "Tethered balloon-born and ground-based measurements of black carbon and particulate profiles within the lower troposphere during the foggy period in Delhi, India," Sci. Total Environ., vol. 573, pp. 894-905, doi: 10.1016/j.scitotenv.2016.08.185.

Brauer H. and Varma YBG, 2012, "Air Pollution Control Equipment”, Springer Berlin Heidelberg, 2012, ISBN: 3642679064

Central Electricity Authority, CEA ANNUAL REPORT - 2018-19, 2019. Retrieved from <http://www.cea.nic.in/reports/annual/annualreports/annual report-2019.pdf>. Last accessed $28^{\text {th }}$ May 2020.

Central Electricity Authority, NORMS FOR INSTALLATION OF FGD for NEW ENVIRONMENTAL REGULATIONS - 7th December-2015, 2019 Retrieved from <http://www.cea.nic.in/reports/others/thermal/umpp/fgd newnorms.pdf $>$. Last accessed $28^{\text {th }}$ May 2020

Central Pollution Control Board, A METHOD TO DETERMINE THE MINIMUM STACK HEIGHT, 1985. Retrieved from <http://cpcbenvis.nic.in/scanned\%20reports/CUPS13\%20A\%20METHOD\%20TO\%20DETERMINE\%20THE\%20MINIMUM\%20STACK\%2OHEIGHT.pdf> Last accessed $28^{\text {th }}$ May 2020.

Chen, C. et al., 2010 "The effectiveness of an air cleaner in controlling droplet/aerosol particle dispersion emitted from a patient's mouth in the indoor environment of dental clinics." J. R. Soc. Interface 7, 1105-1118.

Cohen et al., 2015, "Estimates and 25-year trends of the global burden of disease attributable to ambient air pollution: an analysis of data from the Global Burden of Diseases Study" Lancet, vol. 389, no. 10082, pp. 1907-1918, 2017, doi: 10.1016/S0140-6736(17)30505-6.

Dehbi A., 2006, "Assessment of a new FLUENT model for particle dispersion in turbulent flows" Workshop Proceedings on Benchmarking of CFD...703-720.

George KV, C V Chalapati Rao, P K Labhsetwar and M. Z. Hasan, 2002 “Minimum Stack Height Formula for Coal Based Thermal Power Plant in Northern India" J. Institut. Engineers (India), Environ. Engg. Div., vol. 82, pp 31-34.

Gibson M.D., Soumita Kundu and Mysore Satish, 2013, "Dispersion model evaluation of PM2.5, NOX and SO2 from point and major line sources in Nova Scotia, Canada using AERMOD Gaussian plume air dispersion model", Atmospheric Pollution Research vol. 4, pp 157-167 
Golder D., 1972, "Relations among stability parameters in the surface layer," Boundary-Layer Meteorol., vol. 3, no. 1, pp. 47-58, 1972, doi: 10.1007/BF00769106.

Gorlé, C., van Beeck, J. \& Rambaud, P., 2010, "Dispersion in the Wake of a Rectangular Building: Validation of Two Reynolds-Averaged Navier-Stokes Modelling Approaches." Boundary-Layer Meteorol. 137, 115-133.

Gorlé, C., van Beeck, J., Rambaud, P. \& Van Tendeloo, G., 2009, "CFD modelling of small particle dispersion: The influence of the turbulence kinetic energy in the atmospheric boundary layer." Atmos. Environ. 43, 673-681.

Govardhan G., Satheesh S. K., Nanjundiah R., Moorthy K. K., and Babu S. S., 2017, "Possible climatic implications of high-altitude black carbon emissions," Atmos. Chem. Phys., vol. 17, no. 15, pp. 9623-9644, 2017, doi: 10.5194/acp-17-9623-2017.

Goyal P. and Sidhartha, 2004, "Modeling and monitoring of suspended particulate matter from Badarpur thermal power station, Delhi", Environ. Model. \& Software, vol. 19, pp 383-390.

Gromaszek K., Wójcik W., Kotyra A., Iskakova A., Shegebayeva Z and Talgatkyzy I.B., 2016, "Modelling and analysis of electrostatic precipitator (ESP) in combustion process", Prz Elektrotechniczn, 92(8):121-124

Han J., Arya S. P., Shen S., and Lin Y., 2000 "An Estimation of Turbulent Kinetic Energy and Energy Dissipation Rate Based on Atmospheric Boundary Layer Similarity Theory," Nasa, no. June, 2000.

Hao, J.M., Wang, S.X. and Lu, Y.Q., 2009. Handbook on sulfur dioxide pollution control technology in coal combustion. Chemical Industry, Beijing.

Kim K-D, Naim Hasolli, Kang-San Lee, Jae-Rang Lee and Young-Ok Park, 2019, “Control of Fugitive Fine Coal Particulate Emissions from Coal Handling System at Coal-Fired Power Plants using a Two-Stage Vortex Scrubber", J. Korean Soc. Atmos., Vol. 35, pp. 282-293

Kozić M. S., Ristić S. S., Štetić Kozić S. M., and Polić S. R., 2015, “A numerical study for the assessment of pollutant dispersion from kostolac $b$ power plant to viminacium for different atmospheric conditions," Therm. Sci., vol. 9, no. 2, pp. 425-434, doi: 10.2298/TSCI130115158K.

Li J., Li S. and Zhou F., 2015, "Effect of moisture in coal dust on filtration and cleaning performance of filters", Physicochem. Probl. Mi., Vol. 52, pp 365-379, DOI: $10.5277 /$ ppmp160131

Li X. X., Liu C. H., Leung D. Y. C., and Lam K. M., 2006 "Recent progress in CFD modelling of wind field and pollutant transport in street canyons," Atmos. Environ., vol. 40, no. 29, pp. 5640-5658, 2006, doi: 10.1016/j.atmosenv.2006.04.055.

Ministry of Environment and Forests, 2009, Notification G.S.R. 826 (E)., Gazette of India, Extraordinary, Part 2 Section 3, Ministry of Environment and Forests, Government of India, New Delhi. Retrieved from <http://moef.gov.in/wp-content/uploads/2017/08/826.pdf>

Ministry of Environment, Forest and Climate Change, 2015, Notification (S.O. 3305 (E)., Gazette of India, Extraordinary, Part 2 Section 3, Ministry of Environment, Forest and Climate Change, Government of India, New Delhi. Retrieved from <http://moef.gov.in/wpcontent/uploads/2017/08/Thermal plant gazette scan.pdf> 
MoF (Ministry of Finance), 2018. Enabling Inclusive Growth through Affordable, Reliable and Sustainable Energy (Chapter 9 of Economic Survey). Retrieved from $<$ https://www.indiabudget.gov.in/budget201920/economicsurvey/doc/vol1chapter/echap09 vol1.pdf>

MoP (Ministry of Power), 2018, Emission Norms for Thermal Power Plants, Lok Sabha Starred Question (No.334.) Retrieved from <http://164.100.24.220/loksabhaquestions/annex/15/AS334.pdf>.

Pan S-Y, Pengchen Wang, Qian Chen, Wenju Jiang, Ying-Hao Chu and Pen-Chi Chiang, 2017, "Development of high-gravity technology for removing particulate and gaseous pollutant emissions: Principles and applications" J. Clean. Prod., Vol. 149, pp 540-556.

Randerson D., 2016 "Atmospheric Boundary Layer." US Dep. Energy, Tech. Inf. Center, (Technical Report) DOE/TIC, pp. 147-188, doi: 10.4028/www.scientific.net/amm.820.338.

Riddle A., Carruthers D., Sharpe A., McHugh C., and Stocker J., 2004, "Comparisons between FLUENT and ADMS for atmospheric dispersion modelling," Atmos. Environ., vol. 38, no. 7, pp. 1029-1038, doi: 10.1016/j.atmosenv.2003.10.052.

Sahebnasagh M. R., Esfahanian V., Gitipour S., Ahmadi G., and Ashrafi K., 2008 "Simulation of plume patterns associated with different atmospheric temperature profiles," Asian J. Chem., vol. 20, no. 8, pp. 6551-6564.

Scargiali F., Di Rienzo E., Ciofalo M., Grisafi F., and Brucato A., 2005, "Heavy gas dispersion modelling over a topographically complex mesoscale a cfd based approach," Process Saf. Environ. Prot., vol. 83, no. 3 B, pp. 242-256, doi: 10.1205/psep.04073.

Schnelle Jr, K.B., Brown, C.A. (2016) Design and application of wet scrubbers, Air Pollution Control Technology, CRC Press, 317-341

Sugiyama G. and Nasstrom J. S., 1999, "Methods for determining the height of the atmospheric boundary layer," Lawrence Livermore Natl. Lab., p. 11, 1999, doi: 10.5194/acp-11-6837-2011.

Tessum, M.W., Raynor, P.C., 2017, "Effects of spray surfactant and particle charge on respirable coal dust", Saf. Health Work, vol. 8, pp 296-305, DOI: 10.1016/ j.shaw.2016.12.006

Thomas F W, S B Carpenter and F E Gartrell, 1963 "Stacks-How High?”, J. Air Pollut. Control. Assoc., 13:5, 198-204, DOI: 10.1080/00022470.1963.10468165

Tominaga Y. and Stathopoulos T., 2011, "CFD modeling of pollution dispersion in a street canyon: Comparison between LES and RANS," J. Wind Eng. Ind. Aerodyn., vol. 99, no. 4, pp. 340-348, doi: 10.1016/j.jweia.2010.12.005.

Tominaga Y. and Stathopoulos T., 2018, "CFD simulations of near-field pollutant dispersion with different plume buoyancies," Build. Environ., vol. 131, pp. 128-139, doi:

10.1016/j.buildenv.2018.01.008.

Wang H., Denggao Chen, Zhenshan Li, Dinghai Zhang, Ningsheng Cai, Jin Yang and Geng Wei, 2018, "SO3 Removal from Flue Gas with $\mathrm{Ca}(\mathrm{OH}) 2$ in Entrained Flow Reactors", Energ. Fuel., vol. 32, pp 5364-5373.

Wiatros-Motyka M. 2019, "NOx control for high-ash coal-fired power plants in India", Clean Energy, Vol. 3, No. 1, pp 24-33, doi: 10.1093/ce/zky018 
Xu Yong, Jianlin Hu, Qi Ying, Hongke Hao, Dexiang Wang and Hongliang Zhang, 2015, "Current and future emissions of primary pollutants from coal-fired power plants in Shaanxi, China" Sci. Tot. Environ. Vol. 595, pp 505-514

Zhang X., 2009, CFD simulation of neutral ABL flows (Rise-R-1688). 